\title{
Multi-area economic dispatch with tie-line constraints employing evolutionary approach
}

\author{
Manisha Sharma, Manjaree Pandit*, Laxmi Srivastava \\ ${ }^{1 *}$ Department Department of Electrical Engineering \\ M.I.T.S., Gwalior, INDIA \\ ${ }^{*}$ Corresponding Author: e-mail: manjaree_p@hotmail.com Tel.+91-0751-2665962, +91-0751-2409380
}

\begin{abstract}
Economic dispatch (ED) has the objective of generation allocation to the power generators in such a manner that the total fuel cost is minimized while all operating constraints are satisfied. For the sake of simplicity, ED is generally solved without accounting for transmission constraints. However, in deregulated power system environment it is essential to model the ED problem for practical multi-area cases with tie line constraints. Most of the conventional gradient based methods are time consuming, suffer from dimensionality problem and assume the fuel cost curves of generating units to be piecewise linear, monotonically increasing in nature. The resulting dispatch solutions are therefore inaccurate; sometimes producing infeasible solutions for modern generating units having non convex cost curves. On the other hand evolutionary methods do not suffer from convexity assumptions and achieve fast solutions even for complex non-linear, non-convex, multi-modal optimization problems. This paper reviews and compares some evolutionary techniques for multi-area economic dispatch (MAED). The paper presents an extensive comparison of the search capability and convergence behavior of i) Classical differential evolution (DE) and its various strategies ii) Classical particle swarm optimization (PSO) and iii) An improved PSO with a parameter automation strategy having time varying acceleration coefficients (PSO_TVAC) for solving MAED problems for two area and three area test power systems with 4,10 and 40- generating units. The results are found to be superior compared to some recently published results.
\end{abstract}

Keywords: Differential evolution, Multi-area economic dispatch, multiple fuel options, particle swarm optimization, transmission capacity constraints. Time varying acceleration coefficients (TVAC), Valve point loading effects.

\section{Introduction}

The objective of Economic dispatch (ED) is to allocate power generation among available generators in the most economical manner, while satisfying the physical and operational constraints. The cost of power generation, particularly in fossil fuel plants, is very high and economic dispatch helps in saving a significant amount of revenue. Conventional methods like lamda iteration, base point participation factor, gradient methods etc. rely heavily on the convexity assumption of generator cost curves and hence approximate these curves using quadratic or piecewise quadratic, monotonically increasing cost functions (Wood et al., 1984). In actual practice however, this assumption is not valid because the cost functions exhibit higher order non-linearities and discontinuities due to prohibited operating zones (POZ), ramp rate limits and valve point loading effects (Walter et al., 1993, Orero et al., 1996). In the practical ED, the cost function must be expressed as a piecewise non-linear function in place of a single quadratic function. Therefore, ED problem with valve point effects gives rise to a non smooth optimization problem with heavy equality and inequality constraints, having complex and nonconvex characteristics with multiple minima, which make the challenge of obtaining the global minima very difficult. Most traditional methods fail for this NCED problem except dynamic programming (Shoults et al., 1986) in which no restriction is imposed on the shape of cost curves, but this method suffers from the problem of dimensionality and excessive evaluation at each stage.

Power utilities try to achieve high operating efficiency to produce cheap electricity. Competition exists in the electricity supply industry in generation and in the marketing of electricity. The operating cost of a power pool can be reduced if the areas with more economic units generate larger power than their load, and export the surplus power to other areas with more expensive units. The 
benefits thus gained will depend on several factors like the characteristics of a pool, the policies adopted by utilities, types of interconnections, tie-line limits and load distribution in different areas. Therefore, transmission capacity constraints in production cost analysis are important issues in the operation and planning of electric power systems.

The economic dispatch problem is frequently solved without considering transmission constraints. Compared to the classical ED problem the MAED problem is more complex due to the additional tie-line constraints and area power balance requirements. However, some researchers have taken transmission capacity constraints into consideration. A complete formulation of multi-area generation scheduling with import/export constraints was presented in a reference (Shoults et al., 1980). Desell et al. (1984) proposed an application of linear programming to transmission constrained production cost analysis. Farmer et al. (1990) presented a probabilistic method which was applied to the production costing of transmission constrained multi-area power systems. Hopfield neural network based approach was proposed to solve the MAED problem (Yalcinoz et al., 1998). Doty and McIntyre et al. (1982) solved multi-area economic dispatch problem by using spatial dynamic programming and optimal results were reported considering transmission constraint with linear losses. Linear programming application is proposed in Desell et al. (1984) to production cost analysis with transmission constraint. Area control error is solved in multi-area economic dispatch (Hemick et al., 1985). Wang and Shahidehpour et al. (1992) proposed a decomposition approach for solving multi-area generation scheduling with tie-line constraints using expert systems. They presented efficiency of decomposition approach by testing it on a four area system with each area consisting of 26 units. The Newton-Rapshon's method is applied to solve multi-area economic dispatch problem (Wernerus et al., 1995) by calculating short range margin cost based prices. An incremental network flow programming algorithm was proposed for the MAED solution with tie-line constraints (Streifferet et al., 1995). The MAED is solved by the direct search method with considering transmission constraint (Chen et al., 2001). Evolutionary programming is proposed in Jayabarathi et al. (2000) for multi-area economic dispatch problem. Recently covariance matrix adapted evolutionary strategy has been proposed for MAED problems where a Karush Kuhun Tucker (KKT) optimality based stopping criterion is applied to guarantee optimal convergence (Manoharan et al., 2009). Determining the most economical fuel to burn poses another optimization challenge for generators with multiple fuel options. In such cases the fuel cost curve is represented as a segmented piecewise quadratic function similar to the valve point loading effects (Park et al., 1993). The economic dispatch problem with multiple areas and multiple fuel options translates into a nonconvex optimization problem with complex constraints. Such optimization problems require algorithms which avoid approximation of cost function and still do not require large computational time. The methods found suitable include tabu search, simulating annealing, neural networks (Yalcinoz et al., 1998; Park et al., 1993), genetic algorithm (Orero et al., 1996), particle swarm optimization (Chaturvedi et al., 2009), harmony search (Vasebi et al., 2007), ant colony optimization (Song et al., 1999), bacterial foraging, (Panigrahi et al., 2009), artificial immune system (Vanaja et al., 2008) and differential evolution (DE) (Coelho et al., 2006). Among these techniques, PSO, DE and their variants have been extensively popular due to their superior convergence characteristics, consistency and ease of implementation.

Although these methods do not always guarantee global best solutions, they often achieve a fast and near global optimal solution. Researches have constantly observed that all these methods very quickly find a good local solution but get stuck there for a number of iterations without further improvement sometimes causing premature convergence. Time varying acceleration coefficients (TVAC), (Chaturvedi et al., 2009) are employed countering the effect of premature convergence in PSO. The TVAC strategy strikes a proper balance between the cognitive and social component during the initial and latter part of the search and hence is found to avoid premature convergence of the swarm. The paper aims to test the potential of all the basic DE variants in producing feasible solutions for the MAED problem formulated with many different constraints. The paper also compares the solution quality of DE variants with the PSO_TVAC strategy with classical PSO. The results of all three evolutionary strategies are found to be feasible and superior to reported results (Yalcinoz et al., 1998; Chen et al., 2001; Manoharan et al., 2009).

\section{Multi-area Economic Dispatch with Multiple fuel Options}

The objective of MAED is to determine the generation levels and the power interchange between areas which would minimize total fuel costs in all areas while satisfying power balance, generating limit and transmission capacity constraints. If an area with excess power is not adjacent to a power deficient area, or the tie-line between the two areas is at the transmission limit, it is necessary to find an alternative path between these two areas in order to transmit additional power.

The generator cost function is obtained from the data taken during the heat-run tests, in which the input-output data is measured to cover the operating region. Large turbine generators usually have a number of fuel admission valves which are opened one by one when the unit is called upon to increase production. When a valve is opened, the throttling losses increase rapidly as a result of which, the incremental heat rate rises suddenly. The valve-point effects introduce ripples in the heat-rate curves and make the objective function discontinuous, nonconvex and with multiple minima. The fuel cost of the $i^{\text {th }}$ unit can be calculated as.

$$
F_{i}\left(P_{i}\right)=a_{i} P_{i}^{2}+b_{i} P_{i}+c_{i}+\mid e_{i} \times \sin \left(f_{i} \times\left(P_{i}^{\min }-P_{i}\right)||\right.
$$

When the generating units are supplied with multiple fuel sources, the cost of each unit is represented with several piecewise quadratic functions reflecting the effects of fuel changes; the generator has to identify the most economic fuel to burn from the options available. The fuel cost function for such a case is represented as in Lin et al. (1984). 


$$
F\left(P_{m i}\right)=\left\{\begin{array}{l}
a_{m i 1} P_{m i}^{2}+b_{m i 1} P_{m i}+C_{m i 1}, \ldots \ldots . . i f \ldots . . . P_{m i(\min )} \leq P_{m i} \leq P_{l 1}, \text { fuel..1 } \\
a_{m i 2} P_{m i}^{2}+b_{m i 2} P_{m i}+C_{m i 2,}, \ldots . . i f \ldots . . P_{l 1} \leq P_{m i} \leq P_{l 2}, \text { fuel...2 } \\
\ldots . . \\
\ldots . . \\
a_{m i k} P_{m i}^{2}+b_{m i k} P_{m i}+C_{m i k}, \ldots . . i f \ldots . . P_{m i k-1} \leq P_{m i} \leq P_{m i(\max )}, \text { fuel...k }
\end{array}\right.
$$

where $a_{m i k}, b_{m i k}$ and $c_{m i k}$ are the fuel-cost coefficients of the $i^{\text {th }}$ unit, of $m^{\text {th }}$ area and $k=1,2, \ldots, K$ are the available fuels. The ED problem is to determine the generated powers Pi of units for a total load of PD so that the total fuel cost for the N number of generating units is minimized subject to the power balance constraint and unit upper and lower operating limits. Taking into consideration the cost of transmission though each tie-line, the objective function of multi-area economic dispatch is given in Eq. (3) as

$$
\operatorname{MinF}_{T}=\sum_{i=1}^{N} F_{i}\left(P_{i}\right)+\sum_{j}^{M-1} f_{j} T_{j(M-1)}
$$

$f_{i}$ is the cost function associated with tie line power flow from area $j$ to area $(M-1)$.

i)Area Power Balance Constraints

The power balance constraints for area m neglecting losses can be given as

$$
\sum_{i=1}^{N} P_{i m}=\left(P_{D m}+\sum_{j}^{M-1} T_{j(M-1)}\right)=0
$$

for $m=1,2 \ldots \ldots . . . \mathrm{M}$ (areas). $P_{D m}$ is the load demand in $m^{\text {th }}$ area and $T_{j}$ represents the tie line flows to the $j^{\text {th }}$ area from other areas. ii)Generating Limit Constraints

The power output of a unit must be allocated within the range bounded by its lower and upper limits of real power generation as given by

$P_{i}^{\min } \leq P_{i} \leq P_{i}^{\max } \quad i=1,2, \ldots, N$

iii)Tie-line Limit Constraints

The tie line power flows to area $\mathrm{j}$ should be between the maximum and minimum

$T_{j(M-1)}^{\min } \leq T_{j(M-1)} \leq T_{j(M-1)}^{\max } \quad j=1,2, \ldots, M$

where $T_{j}$ is the power flow through the tie line.

\section{Review of Evolutionary Strategies}

During the last decade different Evolutionary strategies have increasingly been applied by researchers for solving economic dispatch problems (Walter et al., 1993; Orero et al., 1996; Jayabarathi et al., 2000; Coelho et al., 2006; Sinha et al., 2003) due to their powerful search capability and ability to handle different types of cost functions. Out of the different evolutionary techniques proposed PSO and DE have emerged as the most popular, looking at the number of papers published during the past few years. The present paper aims to present a brief review and comparison of both the techniques and their different variants using performance metrics such as convergence behavior, consistency and solution quality for solving the MAED problem with multiple fuel options.

\subsection{Classical PSO}

A PSO is a population based modern heuristic search method that traces its evolution to the emergent motion of a flock of birds searching for food. It scatters random particles i.e. solutions into the problem space. These particles, called swarms, collect information from each other through their respective positions. The particles update their positions using their own experience and the experience of their neighbors. The update mode is termed as the velocity of particles. The position and velocity vectors of the $i^{\text {th }}$ particle of a d-dimensional search space can be represented as $X_{i}=\left(x_{i 1}, x_{i 2}, \ldots \ldots \ldots \ldots X_{i d}\right)$ and $V_{i}=\left(v_{i 1}, v_{i 2}, \ldots \ldots \ldots v_{i d}\right)$ respectively. On the basis of the value of the evaluation function, the previous best position of a particle is recorded and represented as pbest $_{i}=\left(p_{i 1}, p_{i 2} \ldots \ldots . . p_{i d}\right)$ If the $\mathrm{g}^{\text {th }}$ particle is the best among all particles in the group so far, it is represented as pbest $_{g}=$ gbest $=\left(p_{g 1}, p_{g 2}, \ldots \ldots \ldots . . . p_{g d}\right)$ The particle tries to modify its position using the current velocity and the 
distance from pbest and gbest and .The modified velocity and position of each particle for fitness evaluation in the next iteration are calculated using the following equations:

$v_{i d}^{k+1}=C\left[w \times v_{i d}^{k}+c_{1} \times\right.$ rand $_{1} \times\left(\right.$ pbest $\left._{i d}-x_{i d}\right)+c_{2} \times$ rand $_{2} \times\left(\right.$ gbest $\left.\left._{g d}-x_{i d}\right)\right]$

$x_{i d}^{k+1}=x_{i d}+v_{i d}^{k+1}$

Here $\mathrm{w}$ is the inertia weight parameter, $\mathrm{C}$ is constriction factor, $\mathrm{c}_{1}, \mathrm{c}_{2}$ are cognitive and social coefficients, $\operatorname{rand}_{1}$ and rand $_{2}$ are random numbers between 0 and 1 . A large inertia weight helps in good global search while a smaller value facilitates local exploration. Therefore, the practice is to use larger inertia weight factor during initial exploration and gradual reduction of its value as the search proceeds in further iterations. The time varying inertial weight is given by

$w=\left(w_{\text {max }}-w_{\text {min }}\right) \times \frac{\left(\text { iter }_{\max }-\text { iter }\right)}{\text { iter }_{\max }}+w_{\text {min }}$

where iter is the current iteration number while iter $_{\max }$ is the maximum number of iterations. Usually, the value of $w$ is varied between 0.9 and 0.4 .

\subsection{PSO with Time-Varying Acceleration Coefficients (PSO_TVAC)}

Though the PSO technique with time varying inertia weight can locate good solution at a significantly fast rate, its ability to fine tune the optimum solution is weak, mainly due to the lack of diversity at the end of the search. It has been observed by most researchers that in PSO, problem-based tuning of parameters is a key factor to find the optimum solution accurately and efficiently. (Kennedy and Eberhart et al., 1995) stated that a relatively higher value of the cognitive component, compared with the social component, results in roaming of individuals through a wide search space. On the other hand, a relatively high value of the social component leads particles to a local optimum prematurely. In population-based optimization methods, the policy is to encourage individuals to roam through the entire search space during the initial part of the search, without clustering around local optima. During the latter stages, convergence towards the global optima is encouraged, to find the optimal solution efficiently. The idea behind TVAC is to enhance the global search in the early part of the optimization and to encourage the particles to converge towards the global optima at the end of the search. This is achieved by changing the acceleration coefficients $\mathrm{c}_{1}$ and $\mathrm{c}_{2}$ with time in such a manner that the cognitive component is reduced while the social component is increased as the search proceeds. With a large cognitive component and small social component at the beginning, particles are allowed to move around the search space instead of moving toward the population best during early stages. On the other hand, a small cognitive component and a large social component allow the particles to converge to the global optima in the latter part of the optimization process. The acceleration coefficients are expressed as (Ratnaweera et al., 2004):

$$
\begin{aligned}
& c_{1}=\left(c_{1 f}-c_{1 i}\right) \frac{\text { iter }}{\text { iter } \max }+c_{1 i} \\
& c_{2}=\left(c_{2} f-c_{2 i}\right) \frac{\text { iter }}{\text { iter } \max }+c_{2 i}
\end{aligned}
$$

where $c_{1 i}, c_{1 f}, c_{2 i}$ and $c_{2 f}$ are initial and final values of cognitive and social acceleration factors respectively.

\subsection{Differential evolution}

DE is a population-based stochastic function minimizer (or maximizer) based on evolutionary computation, whose simple yet powerful and straightforward features make it very attractive for numerical optimization. DE differs from conventional genetic algorithms in its use of perturbing vectors, which are the difference between two randomly chosen parameter vectors, a concept borrowed from the operators of Nelder and Mead's simplex optimization technique. The DE algorithm was first introduced by Storn and Price et al. (1995) and was successfully applied in the optimization of some well-known nonlinear, non-differentiable, and non-convex functions. DE works on three basic operations, namely mutation, crossover and selection.

Mutation is an operation that adds a vector differential to a population vector of individuals according to the chosen variant. The different variants of $\mathrm{DE}$ are classified using the notation $\mathrm{DE} / \alpha / \beta / \delta$ where $\alpha$ indicates the method for selecting the parent chromosome that will form the base of the mutated vector, $\beta$ indicates the number of difference vectors used to perturb the base chromosome, and $\delta$ indicates the recombination mechanism used to create the offspring population. Most papers have explored the variant DE / rand / 1 / bin (Coelho et al., 2006). The best performing variant is found to be problem specific and needs detailed investigation. The donor or mutant vector for each population member is generated for different variants in classic DE as given below

\section{1) $\mathrm{DE} / \mathrm{rand} / \mathbf{1}$}

$$
Z_{i}(t+1)=x_{i, r 1}(t)+f_{m}\left[x_{i, r 2}(t)-x_{i, r 3}(t)\right]
$$

\section{2) $\mathrm{DE} /$ best/1}

$$
Z_{i}(t+1)=x_{i, b e s t}(t)+f_{m}\left[x_{i, r 2}(t)-x_{i, r 3}(t)\right]
$$




\section{3) $\mathbf{D E} /$ rand-to-best/1}

$$
Z_{i}(t+1)=x_{i}(t)+f_{m}\left[x_{i, b e s t}(t)-x_{i}(t)\right]+f m\left[x_{i} r_{1}(t)-x_{i} r_{2}(t)\right]
$$

4) $\mathrm{DE} / \mathrm{best} / \mathbf{2}$

$$
Z_{i}(t+1)=x_{i \text { best }}(t)+f_{m}\left[x_{i, r 1}(t)-x_{i} r_{2}(t)\right]+f m\left[x_{i} r_{3}(t)-x_{i} r_{4}(t)\right]
$$

5) $\mathrm{DE} / \mathrm{rand} / 2$

$$
Z_{i}(t+1)=x_{i r 5}(t)+f_{m}\left[x_{i, r 1}(t)-x_{i} r_{2}(t)\right]+f m\left[x_{i} r_{3}(t)-x_{i} r_{4}(t)\right]
$$

where $i=1,2 \ldots, R$ is the individual's index of population and $j=1,2, \ldots, N$ is the position in $n$-dimensional individual; $t$ is the time (generation); $r_{1}, r_{2}, r_{3}, r_{4}$ and $r_{5}$ are mutually different integers and also different from the running index, $i$, randomly selected with uniform distribution from the population set and $f_{m}>0$ is a real parameter called mutation factor, which controls the amplification of the difference between two individuals so as to avoid search stagnation and is usually taken from the range [0, 2].Following the mutation operation, recombination is applied to the population. Recombination is employed to generate a trial vector by replacing certain parameters of the target vector with the corresponding parameters of the randomly generated donor vector.

$U_{i j}(t+1)=\left\{\begin{array}{l}Z_{i j}(t+1), \ldots . . i f(\operatorname{rand}(j) \leq C R) \operatorname{or}(j=\operatorname{rand} \operatorname{int}(i)) \\ x_{i j}(t), \ldots \ldots . . . i f(\operatorname{rand}(j)>C R) \operatorname{or}(j \neq \operatorname{rand} \operatorname{int}(i))\end{array}\right.$

In the above $\operatorname{rand}(j)$ is the $j^{\text {th }}$ evaluation of a uniform random number generation within range $[0,1]$, and $C R$ is a crossover or recombination rate in the range $[0,1]$. The performance of a $\mathrm{DE}$ algorithm usually depends on three variables; the population size $N$, the mutation factor $f_{m}$ and the recombination rate $C R$. Selection is the procedure of producing better offspring. To decide whether or not the vector should be a member of the population comprising the next generation, it is compared with the corresponding vector. Thus, it denotes the objective function under minimization, and

$x_{i}(t+1)=\left\{\begin{array}{l}U_{i}(t+1) \ldots \ldots \text { if }\left(u(t+1)<f\left(x_{i}(t)\right)\right. \\ x_{i}(t), \ldots . \text { otherwise }\end{array}\right.$

In this case, the cost of each trial vector $U_{i}(t+1)$ is compared with that of its parent target vector $x_{i}(t)$. Here, a detailed study of all the basic DE variants is carried out to find the best strategy for a given MAED problem with multiple fuel options. The performance is then compared with classical PSO and PSO_TVAC.

\section{Implementation of MAED Problem with Multiple Fuel Option}

The paper presents a solution of the MAED problem with multiple fuel options and valve point loading employing PSO and DE strategies and critically compares their features for practical power system operation.

Step 1) Parameter setup

The PSO and DE parameters such as population size, the boundary constraints of optimization variables, cognitive and social acceleration coefficients, the mutation factor $\left(f_{m}\right)$, the crossover rate $(\mathrm{CR})$, and the stopping criterion of maximum number of iterations $\left(\mathrm{G}_{\max }\right)$, are selected.

Step 2) Initialization of an individual population

For a population size $\mathrm{R}$, the particles are randomly generated and normalized between the maximum and the minimum operating limits of the generators. If there are $\mathrm{N}$ units, the $i^{\text {th }}$ particle is represented as

$P_{i}=\left(P_{i 1}^{n}, P_{i 2}^{n}, P_{i 3}^{n} \ldots \ldots P_{i N}^{n}\left(T_{12} T_{13, \ldots \ldots \ldots \ldots} T_{1 M}\right),\left(T_{23} T_{24, \ldots \ldots .} \ldots T_{2 M}\right) \ldots . T_{(M-1) M}\right)$

The $\mathrm{j}^{\text {th }}$ Dimension of The $\mathrm{i}^{\text {th }}$ Particle is normalized as given below to satisfy the generation limit constraint given by (5). Here, $r$ $[0,1]$.

$$
P_{i j}{ }^{n}=P_{i j \min }+r\left(P_{i j \max }-P_{i j \min }\right)
$$

Step 3) Evaluation of the individual population

The strength of each individual particle in the swarm is evaluated to judge its merit using a fitness function called evaluation function. The evaluation function should be such that cost is minimized while constraints are satisfied. One of the methods for this is the popular penalty function method. In this method, the penalty functions composed of squared or absolute violations are incorporated in the fitness function, and are set to reduce the fitness of the particle according to the magnitude of the violation. The penalty parameters are chosen such that an infeasible solution is awarded lesser fitness than the weakest feasible particle string. Since two infeasible particles are not treated equally, the string further away from the feasibility boundary is more heavily penalized. The penalty function approach, thus, converts a constrained optimization problem into an unconstrained optimization problem. The fitness function values need to be calculated for each particle in order to find its merit. The evaluation function used here is given by 
$\min \sum_{i=1}^{N} F_{i}\left(P_{i}\right)+\alpha\left[\sum_{m=1}^{M} \sum_{i=1}^{N} P_{i m}-\left(P_{D m}+\sum_{j}^{(M-1)} T_{j(M-1)}\right)\right]^{2}$

Here, $\alpha$ is the penalty parameter. The second term imposes a penalty on the particle in terms of increased cost, if power balance constraints of all the areas are not satisfied. The first term is calculated using Fi(Pi) from eq. (1) for solution considering the valve point effects and eq. (2) for units with multiple fuel options. Transmission losses are neglected here for the sake of simplicity.

Step 4) Iterative Parameter Updation

In each iteration the parameters are updated to improve the fitness. In PSO the parameters are updated using eq. (7)-Eq. (11) while in DE mutation adds a vector differential to a population vector of individuals; the donor or mutant vector is generated by using eq. (12) corresponding to the chosen DE variant.

Step 5) Recombination operation

Recombination is applied in DE using eq. (13) to generate a trial vector by replacing certain parameters of the target vector with the corresponding parameters of the randomly generated donor in step 4.

Step 6) Selection operation

Finally the selection operation produces better offspring. The values of the evaluation function are calculated for the updated positions of the particles. In PSO if the new value is better than the previous pbest, the new value is set to pbest. Similarly, value of gbest is also updated as the best of pbest. In DE the trial vector $U_{i}(t+1)$ replaces its parent target vector $x_{i}(t)$ if its cost is found to be better otherwise the target vector is allowed to advance to the next generation.

Step 7) Stopping criterion: A stochastic optimization algorithm is stopped either based on the tolerance limit or maximum number of iterations. For comparison with other strategies, the number of iterations is adopted as the stopping criterion in this paper.

\section{Results and Discussion}

The additional tie-line constraints and area power balance constraints make the MAED problem much more complex and difficult to solve as compared to the classical ED problem. The PSO and DE based evolutionary strategies are tested for the proposed practical MAED problem on three test systems having different sizes and nonlinearities. The performance was compared with previously published results (Yalcinoz et al., 1998; Chen et al., 2001 and Manoharan et al., 2009) and was found to be better.

\subsection{Description of the test systems}

i) The first test system consists of a two-area system with four generating units (Yalcinoz et al., 1998; Chen et al., 2001) as shown in Fig. 1. This system is considered here for the purpose of comparison with previous results. The percentage of the total load demand in area 1 is $70 \%$ and $30 \%$ in area 2 . The cost coefficients and limits are taken from (Chen et al., 2001). The load demand (PD) and tie-line flow limit are set at $1120 \mathrm{MW}$ and 200MW respectively. The global best for this system has been reported at $\$ 10,605$ (Yalcinoz et al.1998, Chen et al.2001) . Reference (Manoharan et al., 2009) has reported \$10,574 but the reported results are infeasible because though their solutions satisfy the power balance and generating limit constraints, it does not satisfy the area power balance constraints.

ii) The second system (Manoharan et al., 2009, Lin et al., 1984) comprises of three areas, 10 generating units, with three fuel options. The total system demand is $2700 \mathrm{MW}$. The 10 generating units are divided into three areas, as shown in Fig. 2. Area 1 comprises the first four units (P1, P2, P3, P4); area 2 includes three units (P5, P6, P7); and area 3 has the remaining three units (P8, $\mathrm{P9}$, P10). Each area has both generation and load and each area is represented as having tie-line connections to each of the other areas. The load demand in area 1 is assumed as $50 \%$ of the total demand. The load demand in area 2 is assumed as $25 \%$ and in area 3 the load is $25 \%$ of the total demand. The tie line flow limit is set at $\pm 100 \mathrm{MW}$ for each tie line. The global best for this system has not yet been reported. The minimum cost for this system using covariance matrix adapted evolutionary strategy (CMAES) technique (Manoharan et al., 2009 ) is $\$ 686.9850$ which is infeasible as area power balance constraints are not satisfied in this case too. DE and PSO_TVAC algorithms used in this paper have achieved lower and feasible results for this system.

iii) Test system three was selected for testing the performance of the evolutionary methods for MAED problem of a large system. This system has 40-generating units with valve point loading effects taken from (Sinha et al., 2003), randomly distributed into two areas such that both areas include half the units. The total system load is 10,500MW (Sinha et al., 2003). The classical PSO is not able to find the best solution for this system but DE and PSO_TVAC converge to global best solutions. 
For the purpose of comparison the cost of tie-line power flow is neglected in all three test cases. In classical PSO both the acceleration coefficients are taken equal to 1.5 for all systems. Simulations were carried out using MATLAB 7.0.1 on a Pentium IV processor, $2.8 \mathrm{GHz}$. with $512 \mathrm{MB}$ RAM.

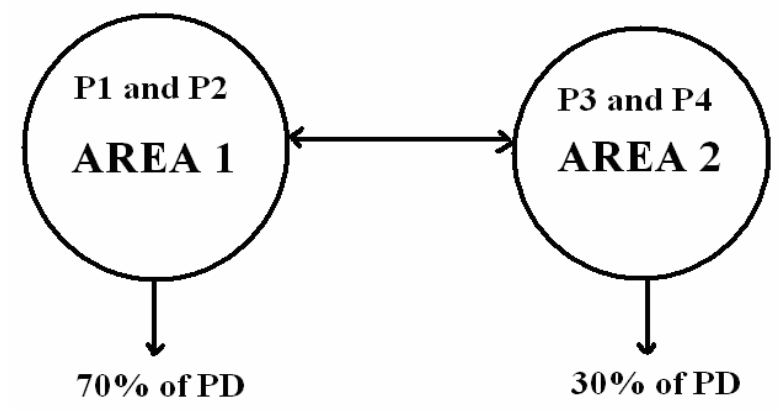

Figure 1.Two-area, four unit system.

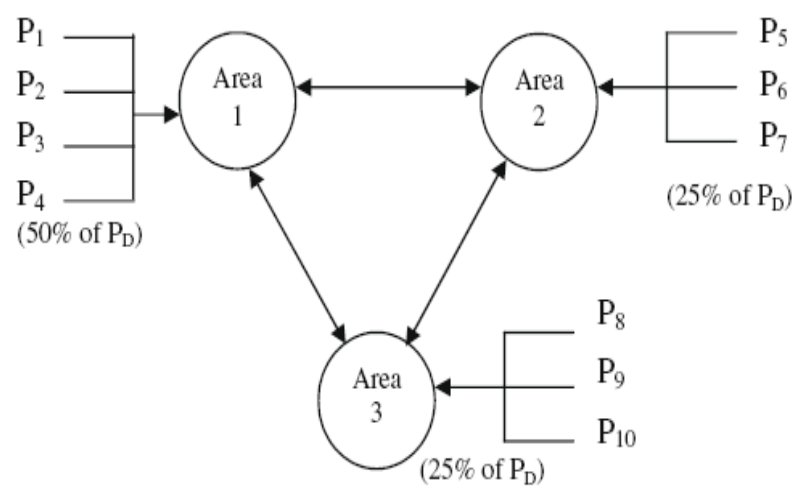

Figure 2. Three area ten generating unit system.

\subsection{Testing Strategies}

The MAED problem was solved using the classical PSO, PSO_TVAC and DE and their performance was compared with some already reported results (Yalcinoz et al., 1998; Chen et al., 2001; Manoharan et al., 2009). During recent years DE and its hybrid variants have been proposed for many power system applications but a detailed comparative study of all its basic variants for MAED problem with complex constraints has not been reported yet. The paper i) Compares different DE variants for the MAED problem ii) Compares the best DE variant with its close competitor PSO and its effective variant PSO_TVAC iii) Investigates the influence of tie-line power limits on the total fuel cost. Through out this paper DE/rand to best/1 variant of DE is applied for comparison with PSO and PSO_TVAC as it was found to be the best among various DE variants defined by eq. (12).

\subsection{Effect of tuning parameters}

An attempt has been made here to compare the PSO and DE strategies extensively, to find similarities and differences; merits and shortcomings; solution quality and consistency and dependence on tuning parameters. A deeper understanding of these strategies can save a lot of time and effort which is otherwise wasted in tuning the different parameters of these algorithms. The mean and standard deviation (S.D.) out of 50 trials for DE algorithm are tabulated in Table 1 for 4-unit system and in Table 2 for 10-unit system. From both the tables it is evident that better results are available for fm and CR pairs lying in a diagonal. Higher fm supports higher $\mathrm{CR}$ and best results are obtained for $f_{m}=\mathrm{CR}=0.9$ (and/or 0.8 ) for both the systems. This behavior was found to be consistent for other mathematical benchmark problems too. It can be seen from the two tables that for some combinations of fm and CR, the DE algorithm did not converge.

Similar to DE and other evolutionary techniques, the performance of PSO algorithm is quite sensitive to the various parameter settings. The initial and final values of the acceleration coefficients have a significant effect on the solution. Based on empirical studies on a number of mathematical benchmarks, reference (Ratnaweera et al., 2004) has reported the best range of variation as 2.5-0.5 for $c_{1}$ and 0.5-2.5 for $c_{2}$. In reference (Chaturvedi et al., 2008). It is observed that initial value of the cognitive coefficient 
cli and final value of social coefficient $c_{2 f}$ control the range of the search space. Therefore in PSO_TVAC the values of $c_{1 i}$ and $c_{2 f}$ are varied between 2.5-1.8 keeping $\mathrm{c}_{1 \mathrm{f}}$ and $\mathrm{c}_{2 \mathrm{i}}$ fixed at 0.2 (Chaturvedi et al., 2008). It is seen that a high initial value of the cognitive coefficient $c_{1}$ makes use of full range of the search space while a low social coefficient $c_{2}$ helps in avoiding premature convergence. As the search progresses $c_{1}$ is reduced to reduce search space and $c_{2}$ is increased to accelerate the solution towards global convergence. The best parameter combination is found to depend on the nature of the objective function. However all the tested functions were found to achieve optimal results in the above variation range of $c_{1}$ and $c_{2}$.

Table 3 and Table 4 present the effect of acceleration coefficients on the MAED solution of 4-unit and 10-unit system by PSO_TVAC strategy. It can be seen that for all combinations of $\mathrm{c}_{1 \mathrm{i}}$ and $\mathrm{c}_{2 \mathrm{f}}$ around 2.0, the PSO_TVAC strategy converges to near global results indicated by a small value of S.D. Best results in this case are found for $\mathrm{c} 1 \mathrm{i}=\mathrm{c} 2 \overline{\mathrm{f}}=1.8$. On comparison of DE with PSO_TVAC it can be seen that DE converges to the global solution for $f_{m}=\mathrm{CR}=0.9$ for both the test systems with zero S.D. but for other values of fm and CR the S.D. is quite high, sometimes indicating non convergence. To summarize, it can be said that DE is capable of producing guaranteed global best results accurately for $\mathrm{fm}=\mathrm{CR}=0.9$ while PSO_TVAC converges to near global values for all combinations of tuning parameters; the global best is also achieved in PSO_TVAC for some of the runs but the optimal parameter combination for achieving global best is problem specific, based on trial and error. The S.D. of PSO_TVAC is also higher than that of DE.

Table 1. Effect of mutation factor and cross over rate on mean and S.D.in DE (4-unit system; 50 Trials)

\begin{tabular}{|c|c|c|c|c|c|c|}
\hline F & $\mathrm{CR}=0.1$ & $\mathrm{CR}=0.2$ & $\mathrm{CR}=0.3$ & $\mathrm{CR}=0.5$ & $\mathrm{CR}=0.7$ & $\mathrm{CR}=0.9$ \\
\hline 0.1 & $\begin{array}{l}10810 \\
(99.6394)^{*}\end{array}$ & $\begin{array}{l}10733 \\
(39.0909)\end{array}$ & $\begin{array}{l}10711 \\
(33.6134)\end{array}$ & $\begin{array}{l}10685 \\
(28.4186)\end{array}$ & $\begin{array}{l}10719 \\
(35.7129)\end{array}$ & $\begin{array}{l}10729 \\
(38.2988)\end{array}$ \\
\hline 0.2 & $\begin{array}{l}10880 \\
(357.3825)\end{array}$ & $\begin{array}{l}10828 \\
(104.5888)\end{array}$ & $\begin{array}{l}10749 \\
(43.8385)\end{array}$ & $\begin{array}{l}10696 \\
(27.8735)\end{array}$ & $\begin{array}{l}10714 \\
(34.2938)\end{array}$ & $\begin{array}{l}1013706 \\
(1965906)\end{array}$ \\
\hline 0.3 & $\begin{array}{l}12255 \\
(1194.103)\end{array}$ & $\begin{array}{l}11063 \\
(289.4027)\end{array}$ & $\begin{array}{l}10804 \\
(74.0974)\end{array}$ & $\begin{array}{l}10686 \\
(33.3560)\end{array}$ & $\begin{array}{l}10718 \\
(35.2041)\end{array}$ & $\begin{array}{l}10738 \\
(42.5106)\end{array}$ \\
\hline 0.5 & $\begin{array}{l}15154 \\
(3522.145)\end{array}$ & $\begin{array}{l}13241 \\
(2111.83)\end{array}$ & $\begin{array}{l}10126 \\
(355.7964)\end{array}$ & $\begin{array}{l}10654 \\
(31.2656)\end{array}$ & $\begin{array}{l}10652 \\
(26.1138)\end{array}$ & $\begin{array}{l}10678 \\
(28.8017)\end{array}$ \\
\hline 0.7 & $\begin{array}{l}23134 \\
(11299.48)\end{array}$ & $\begin{array}{l}14234 \\
(3249.13)\end{array}$ & $\begin{array}{l}12046 \\
(12959)\end{array}$ & $\begin{array}{l}10654 \\
(32.1260)\end{array}$ & $\begin{array}{l}10613 \\
(13.3654)\end{array}$ & $\begin{array}{l}10622 \\
(25.2936)\end{array}$ \\
\hline 0.9 & $\begin{array}{l}35033 \\
(23422.788)\end{array}$ & $\begin{array}{l}15326 \\
(4809.67)\end{array}$ & $\begin{array}{l}13025 \\
(2941.9)\end{array}$ & $\begin{array}{l}10672 \\
(47.2911)\end{array}$ & $\begin{array}{l}10612 \\
(13.2254)\end{array}$ & $\begin{array}{l}10604.6740 \\
(7.4942 \mathrm{e}-012)\end{array}$ \\
\hline
\end{tabular}

*the bracketed value indicates the standard deviation

Table 2. Effect of mutation factor and cross over rate on mean and S.D.in DE (10-unit system; 50 Trials)

\begin{tabular}{|c|c|c|c|c|c|c|}
\hline$f_{m}$ & $\mathrm{CR}=0.1$ & $\mathrm{CR}=0.2$ & $\mathrm{CR}=0.3$ & $\mathrm{CR}=0.5$ & $\mathrm{CR}=0.7$ & $\mathrm{CR}=0.9$ \\
\hline 0.1 & $\begin{array}{l}683.9946 \\
(10.7250)^{*}\end{array}$ & $\begin{array}{l}694.9258 \\
(18.4492)\end{array}$ & $\begin{array}{l}686.9954 \\
(12.1843)\end{array}$ & $\begin{array}{l}29462607 \\
(30113007)\end{array}$ & $\begin{array}{l}268654598 \\
(193060087)\end{array}$ & $\begin{array}{l}112560609 \\
(405980089)\end{array}$ \\
\hline 0.2 & $\begin{array}{l}705.6402 \\
(18.5378)\end{array}$ & $\begin{array}{l}689.7573 \\
(14.3429)\end{array}$ & $\begin{array}{l}697.9706 \\
(17.9246)\end{array}$ & $\begin{array}{l}6714506 \\
(10742007)\end{array}$ & $\begin{array}{l}12243007 \\
(14691076)\end{array}$ & $\begin{array}{l}343786708 \\
(145408008)\end{array}$ \\
\hline 0.3 & $\begin{array}{l}734.8387 \\
(42.3935)\end{array}$ & $\begin{array}{l}771.7220 \\
(47.3775)\end{array}$ & $\begin{array}{l}1007.88 \\
(173.1886)\end{array}$ & $\begin{array}{l}757.8291 \\
(45.2385)\end{array}$ & $\begin{array}{l}698.0343 \\
(19.3298)\end{array}$ & $\begin{array}{l}13198007 \\
(15668007)\end{array}$ \\
\hline 0.5 & $\begin{array}{l}1164.93 \\
(281.8871)\end{array}$ & $\begin{array}{l}1827.665 \\
(384.4720)\end{array}$ & $\begin{array}{l}1541.23 \\
(299.2481)\end{array}$ & $\begin{array}{l}4897.49 \\
(2932.63)\end{array}$ & $\begin{array}{l}705.5082 \\
(17.0304)\end{array}$ & $\begin{array}{l}657.7347 \\
(10.5408)\end{array}$ \\
\hline 0.7 & $\begin{array}{l}2109.80 \\
(653.3723\end{array}$ & $\begin{array}{l}3222.70 \\
(630.7551)\end{array}$ & $\begin{array}{l}3498.97 \\
(585.2700)\end{array}$ & $\begin{array}{l}12694.89 \\
(7510.73)\end{array}$ & $\begin{array}{l}820.2417 \\
(68.8499)\end{array}$ & $\begin{array}{l}638.2807 \\
(1.0305)\end{array}$ \\
\hline 0.9 & $\begin{array}{l}2754.73 \\
(1326.35)\end{array}$ & $\begin{array}{l}9109.40 \\
(4555.58)\end{array}$ & $\begin{array}{l}16316.94 \\
(5649.03)\end{array}$ & $\begin{array}{l}36463.64 \\
(14289.74)\end{array}$ & $\begin{array}{l}6774.00 \\
(8018.33)\end{array}$ & $\begin{array}{l}638.3134 \\
(1.0288)\end{array}$ \\
\hline
\end{tabular}

*the bracketed value indicates the standard deviation 
Table 3. Effect of acceleration coefficients on performance of PSO_TVAC (4 unit system ; 50 trials)

\begin{tabular}{|c|c|c|c|c|c|c|c|c|}
\hline S.No. & $c_{l i}$ & $c_{\text {if }}$ & $c_{2 i}$ & $c_{2 f}$ & $\begin{array}{l}\text { Minimum } \\
\operatorname{Cost}(\$ / h)\end{array}$ & $\begin{array}{l}\text { Average } \\
\operatorname{cost}(\$ / h)\end{array}$ & $\operatorname{Max} \operatorname{cost}(\$ / \mathrm{h})$ & S.D. \\
\hline 1 & \multirow{4}{*}{2.5} & 0.2 & 0.2 & 2.5 & 10609.6667 & 10817.648 & 10917.5782 & 71.1407 \\
\hline 2 & & 0.2 & 0.2 & 2.2 & 10607.6732 & 10755.6347 & 10907.8235 & 69.2345 \\
\hline 3 & & 0.2 & 0.2 & 1.9 & 10608.6667 & 10815.4927 & 10905.6529 & 70.3498 \\
\hline 4 & & 0.2 & 0.2 & 1.6 & 10607.7735 & 10803.2487 & 10875.8723 & 68.2745 \\
\hline 5 & \multirow{4}{*}{2.2} & 0.2 & 0.2 & 2.5 & 10608.9701 & 10796.095 & 10864.7893 & 58.167 \\
\hline 6 & & 0.2 & 0.2 & 2.2 & 10608.7812 & 10698.4685 & 10876.3468 & 66.7386 \\
\hline 7 & & 0.2 & 0.2 & 1.9 & 10609.3489 & 10657.4768 & 10748.3578 & 49.9442 \\
\hline 8 & & 0.2 & 0.2 & 1.6 & 10605.3583 & 10695.8690 & 10859.8603 & 68.3472 \\
\hline 9 & \multirow{4}{*}{2} & 0.2 & 0.2 & 2.5 & 10606.5983 & 10774.6503 & 10885.5079 & 64.6315 \\
\hline 10 & & 0.2 & 0.2 & 2.2 & 10606.0085 & 10784.0247 & 10905.8432 & 66.3462 \\
\hline 11 & & 0.2 & 0.2 & 1.9 & 10605.0443 & 10738.8490 & 10870.3476 & 54.5689 \\
\hline 12 & & 0.2 & 0.2 & 1.6 & 10605.4114 & 10749.5489 & 10807.8395 & 50.6521 \\
\hline 13 & \multirow{4}{*}{1.8} & 0.2 & 0.2 & 2.5 & 10605.0248 & 10746.5799 & 10812.5908 & 30.5683 \\
\hline 14 & & 0.2 & 0.2 & 2.2 & 10604.8452 & 10734.5678 & 10810.8909 & 28.5578 \\
\hline 15 & & 0.2 & 0.2 & 1.9 & 10604.6781 & 10717.5431 & 10864.3588 & 27.8354 \\
\hline 16 & & 0.2 & 0.2 & 1.7 & 10604.8250 & 10719.5367 & 10864.3459 & 27.9487 \\
\hline
\end{tabular}

Table 4. Effect of acceleration coefficients on performance of PSO_TVAC (10 unit system ; 50 trials)

\begin{tabular}{|c|c|c|c|c|c|c|c|c|}
\hline S.No. & $c_{I i}$ & $c_{\text {lf }}$ & $c_{2 i}$ & $c_{2 f}$ & $\begin{array}{l}\text { Minimum } \\
\operatorname{Cost}(\$ / h)\end{array}$ & $\begin{array}{l}\text { Average } \\
\operatorname{cost}(\$ / h)\end{array}$ & $\operatorname{Max} \operatorname{cost}(\$ / h)$ & S.D. \\
\hline 1 & \multirow{4}{*}{2.5} & 0.2 & 0.2 & 2.5 & 651.4823 & 723.5144 & 820.8545 & 28.9526 \\
\hline 2 & & 0.2 & 0.2 & 2.2 & 653.6663 & 732.4137 & 817.8545 & 30.6502 \\
\hline 3 & & 0.2 & 0.2 & 1.9 & 664.4861 & 727.2150 & 810.4392 & 24.6154 \\
\hline 4 & & 0.2 & 0.2 & 1.6 & 674.4861 & 730.6202 & 807.6596 & 26.1154 \\
\hline 5 & \multirow{4}{*}{2.2} & 0.2 & 0.2 & 2.5 & 667.4167 & 714.0780 & 811.4392 & 28.6167 \\
\hline 6 & & 0.2 & 0.2 & 2.2 & 654.7213 & 716.8977 & 786.5988 & 21.9986 \\
\hline 7 & & 0.2 & 0.2 & 1.9 & 648.1626 & 725.3440 & 805.8798 & 26.1154 \\
\hline 8 & & 0.2 & 0.2 & 1.6 & 657.8305 & 714.5460 & 777.3873 & 22.8756 \\
\hline 9 & \multirow{4}{*}{2} & 0.2 & 0.2 & 2.5 & 649.0590 & 715.3508 & 804.9547 & 26.4128 \\
\hline 10 & & 0.2 & 0.2 & 2.2 & 648.8459 & 714.2288 & 790.2899 & 22.3930 \\
\hline 11 & & 0.2 & 0.2 & 1.9 & 659.1083 & 713.8741 & 770.1692 & 21.3704 \\
\hline 12 & & 0.2 & 0.2 & 1.6 & 646.4651 & 708.4158 & 787.3428 & 23.2639 \\
\hline 13 & \multirow{4}{*}{1.8} & 0.2 & 0.2 & 2.5 & 647.5590 & 718.0856 & 814.4787 & 27.4898 \\
\hline 14 & & 0.2 & 0.2 & 2.2 & 640.7223 & 724.4681 & 803.2147 & 28.2623 \\
\hline 15 & & 0.2 & 0.2 & 1.9 & 637.5915 & 647.4455 & 694.4076 & 22.2389 \\
\hline 16 & & 0.2 & 0.2 & 1.6 & 643.4693 & 725.1177 & 810.0181 & 28.5387 \\
\hline
\end{tabular}




\subsection{Effect of population size}

In addition to tuning parameters, the population size is another important issue in stochastic search based optimization methods. Studies have been carried out on the role of population size and it has been reported that increasing population improved the performance of PSO algorithm (Chaturvedi et al., 2008, Alrashidi et al., 2007). The optimal population size depends on the problem dimension. Reference (Storn and Price et al., 1997) suggested a population size of 5-10 times that of the problem dimension. It was shown that for various ED problems, larger the dimension, larger is the population size required to achieve good results, (Noman et al., 2008).

In this paper, tests were carried out for different population sizes and results are tabulated in Table 5 and Table 6 for 4-unit and 10-unit systems for the DE algorithm. In Table 7 and Table 8 the results of the two test systems for PSO_TVAC algorithm are presented. The DE algorithm converges to the global best solution for the 4-unit system for a population size of 20 with a S.D. of 7.31. However when the population is increased to 25, the S.D. becomes zero. Similar results are found for the 3-area, 10-unit, test system with multiple fuels. The system was found to converge with zero S.D. for a population size of 120 . For the 40-unit system a population size of 1000 was found to be optimum for PSO_TVAC. The DE algorithm converged for a population of 200. However, the S.D. was found to increase for DE as well as PSO_TVAC for the larger system.

Table 5. Effect of population size on performance of DE ( 4 unit system; 50 trials) $(\mathrm{F}=\mathrm{CR}=0.9)$

\begin{tabular}{|l|l|l|l|l|}
\hline Population & Minimum Cost & Mean Cost & Maximum Cost & S.D. \\
\hline 5 & 10623.3464 & 52090783.9498 & 16944434366.7507 & 852287008.4450 \\
\hline 10 & 10605.6387 & 10680.2010 & 10860.2458 & 44.3875 \\
\hline 20 & 10604.6740 & 10620.2195 & 10760.1419 & 7.3176 \\
\hline 25 & 10604.6740 & 10604.6740 & 10604.6740 & $7.2760 \mathrm{e}-012$ \\
\hline
\end{tabular}

Table 6. Effect of population size on performance of $\mathrm{DE}$ (10- unit system ; 50 trials) ( $\mathrm{F}=\mathrm{CR}=0.9)$

\begin{tabular}{|l|l|l|l|l|}
\hline Population & Minimum Cost & Mean Cost & Maximum Cost & S.D. \\
\hline 10 & 674.5913 & 3006706.6734 & 15031007.3091 & 4809606.6783 \\
\hline 20 & 663.2747 & 717.6755 & 762.7483 & 24.8071 \\
\hline 50 & 642.3585 & 672.5037 & 713.2984 & 24.1987 \\
\hline 110 & 637.4111 & 637.6007 & 638.3001 & 0.2797 \\
\hline 120 & 637.4111 & 637.4111 & 637.4111 & $3.9563 \mathrm{e}-012$ \\
\hline
\end{tabular}

Table 7. Effect of population size on performance of PSO_TVAC (4 unit system ; 50 trials)

\begin{tabular}{|c|r|r|r|r|}
\hline Population & Minimum Cost & \multicolumn{1}{|c|}{ Mean Cost } & Maximum Cost & \multicolumn{1}{|c|}{ S.D. } \\
\hline 5 & 10623.3464 & 20783.9498 & 36366.7507 & 8522.4450 \\
\hline 10 & 10605.6387 & 10680.2010 & 10860.2458 & 44.3875 \\
\hline 20 & 10604.6740 & 10620.2195 & 10760.1419 & 7.3176 \\
\hline 25 & 10604.6740 & 10604.6740 & 10604.6740 & $7.2760 \mathrm{e}-012$ \\
\hline
\end{tabular}

Table 8. Effect of population size on performance of PSO_TVAC (10 unit system; 50 trials)

\begin{tabular}{|c|r|r|r|r|}
\hline $\begin{array}{c}\text { Population } \\
\text { Size }\end{array}$ & Minimum Cost & Mean Cost & Maximum Cost & S.D. \\
\hline 10 & 662.0611 & 6218606.5325 & 220890879.2353 & 1193.4538 \\
\hline 25 & 659.8983 & 714.3048 & 773.7123 & 23.3584 \\
\hline 50 & 658.1030 & 714.4209 & 789.7930 & 25.4602 \\
\hline 100 & 655.4841 & 710.9050 & 793.4703 & 21.0466 \\
\hline 200 & 655.1745 & 710.9297 & 791.3363 & 25.5107 \\
\hline 400 & 637.5915 & 647.4455 & 694.4076 & 22.2389 \\
\hline
\end{tabular}




\subsection{Convergence characteristics}

To test the convergence behavior of the evolutionary strategies under study, i.e. DE, PSO and PSO_TVAC the convergence test was carried out employing the same evaluation function and same initial population for the same number of iterations. The results for all three strategies for one trial of 100 iterations are shown in Fig. 3 and Fig. 4 for the 4-unit and 10-unit systems respectively. It can be seen that the TVAC strategy provides the PSO algorithm with optimal search capability due to the proper tuning of social and cognitive coefficients during the search. When search advances and reaches a certain iteration count, the classical PSO characteristic saturates but the PSO_TVAC still continues to improve and thus shows the best convergence characteristics. It is seen that DE takes longer to converge than PSO_TVAC.

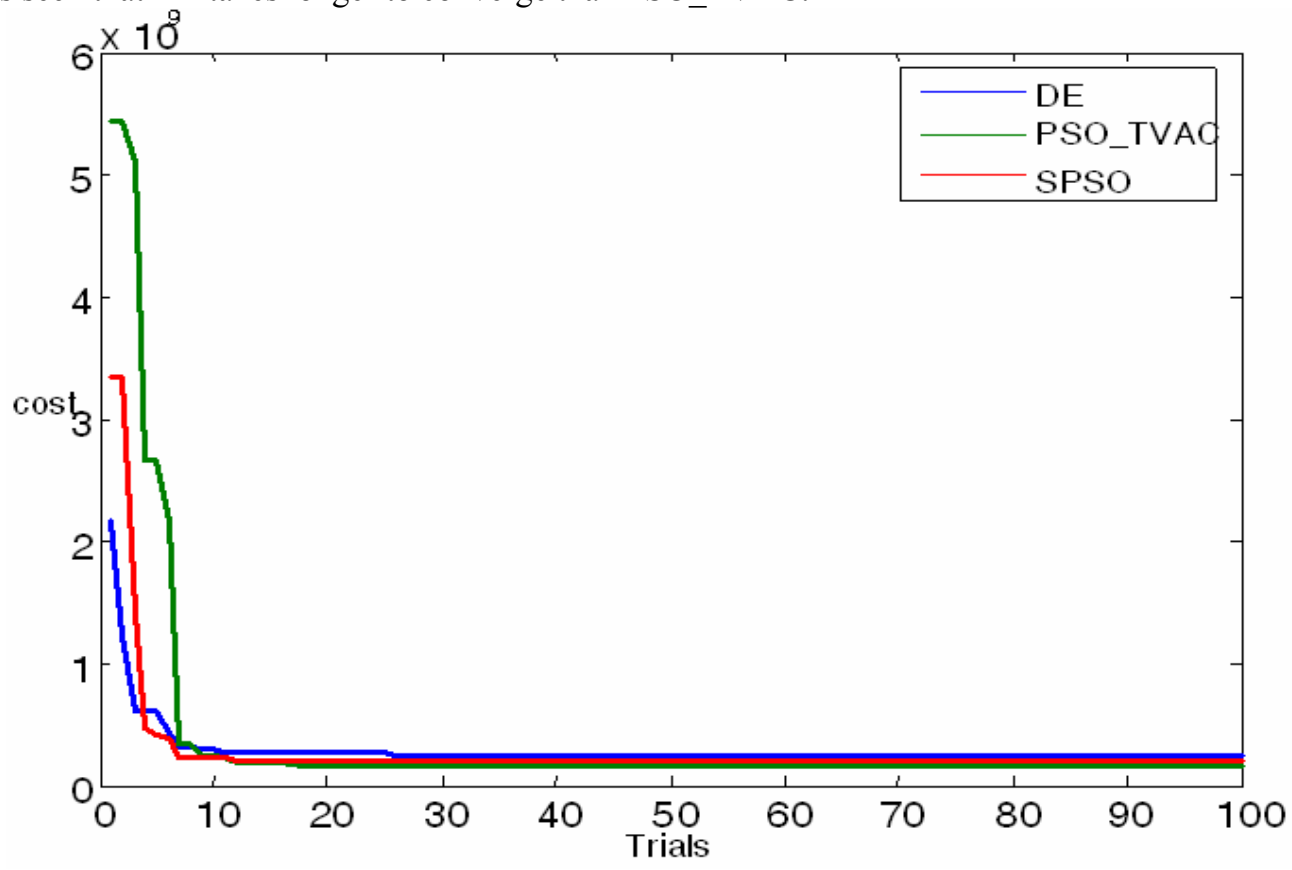

Figure 3. Convergence characteristics of the three evolutionary strategies. (4-unit system)

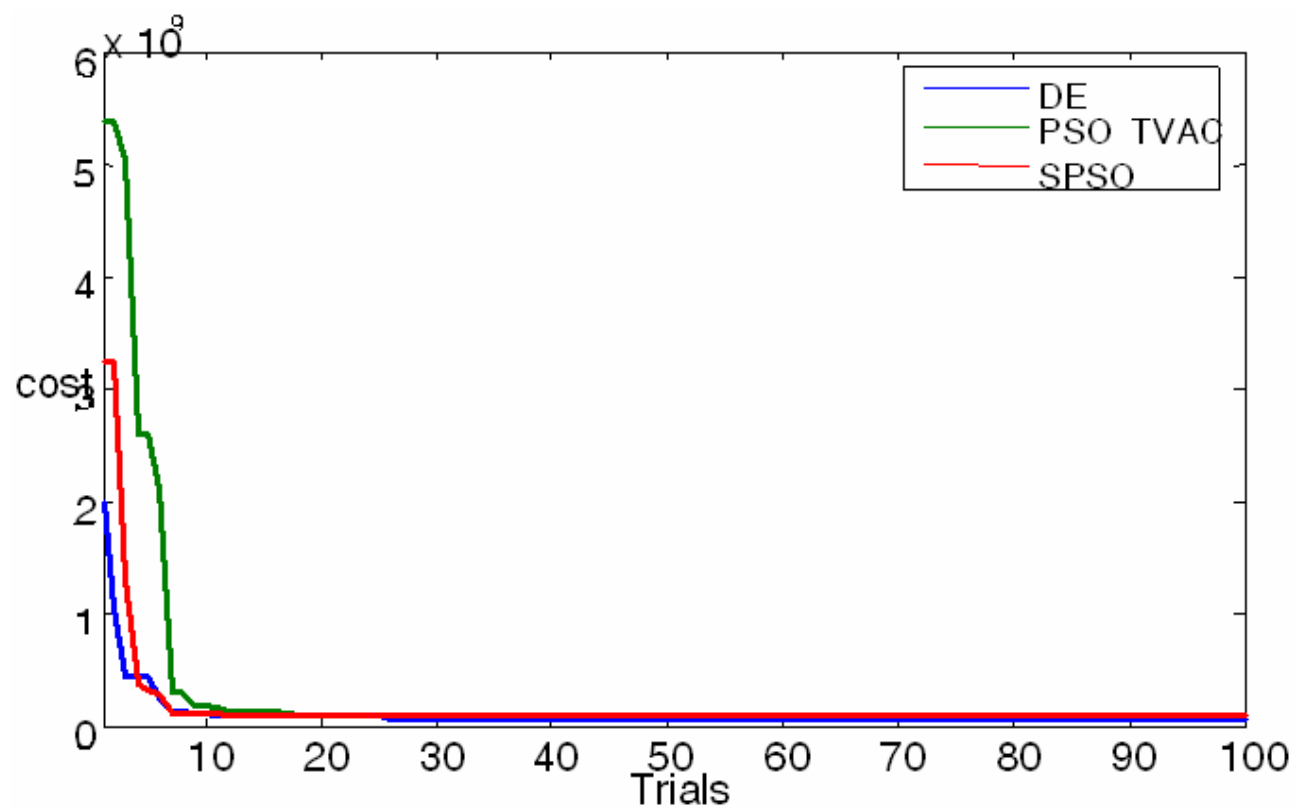

Figure 4. Convergence characteristics of the three evolutionary strategies. (10-unit system) 


\subsection{Robustness}

The performance of heuristic search based optimization algorithms is not judged by the results of a single trial due to the randomness involved in its functioning. Many trials with different initial populations were carried out to test the robustness/consistency of the different evolutionary algorithms. The lowest cost for each of the 50 different trials has been plotted in Fig. 5 and Fig. 6 from which it can be seen that DE produces lowest cost with zero standard deviation indicating its highest consistency. The PSO_TVAC performs much better than classical PSO as it achieved near best results in many trials.

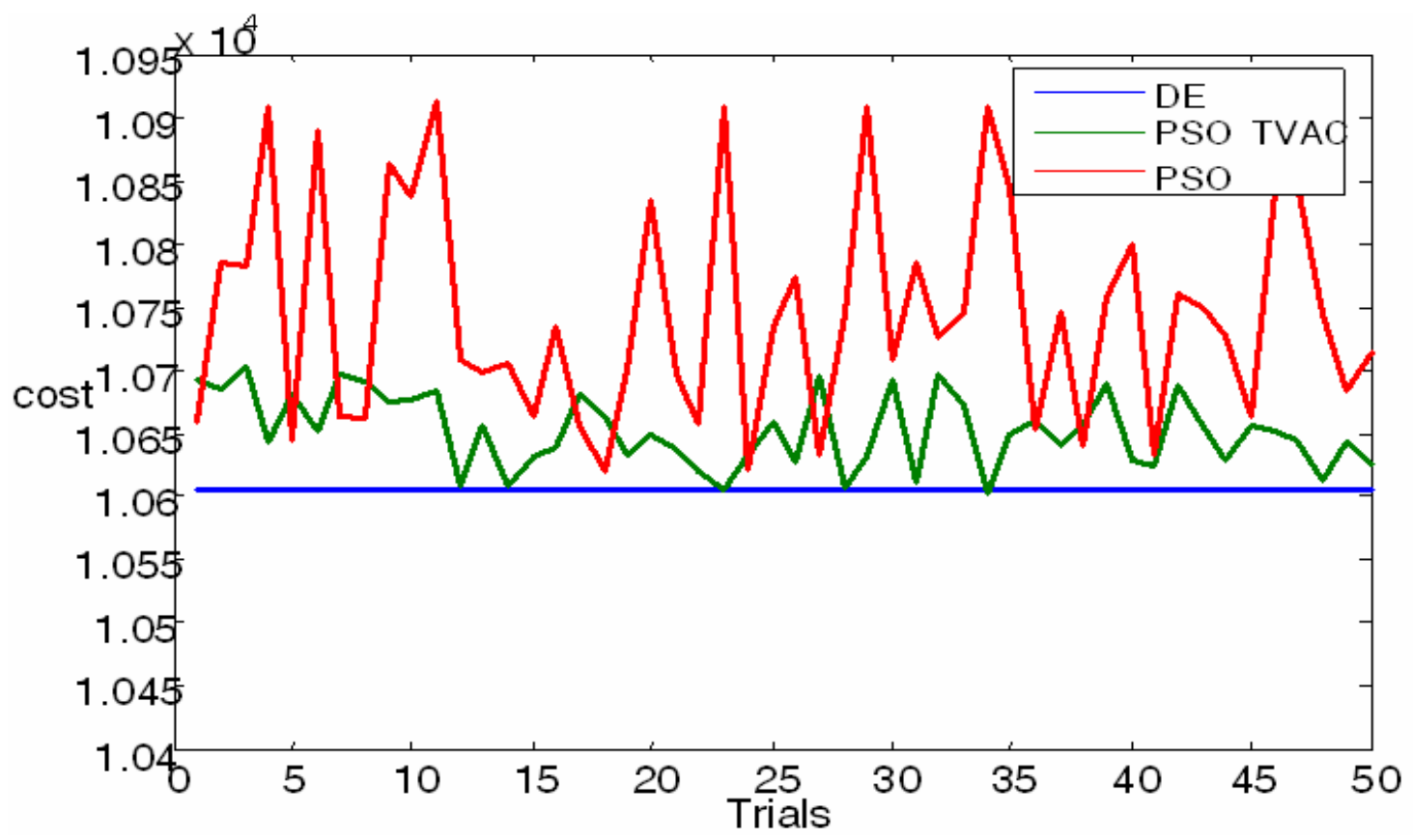

Figure 5. Best results of DE, PSO and PSO_TVAC variants (4-unit system); 50 trials

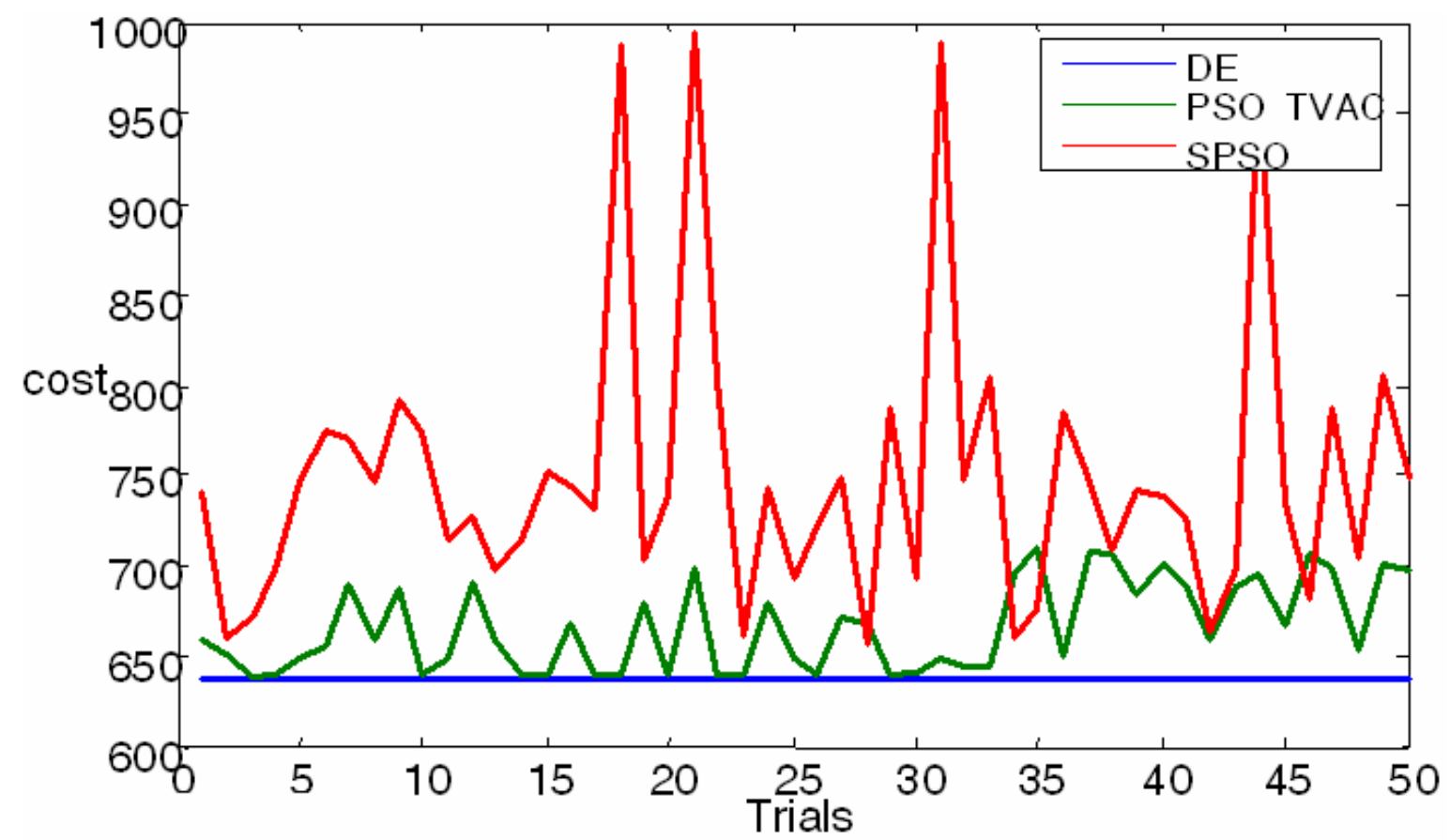

Figure 6. Best results of DE, PSO and PSO_TVAC variants (10-unit system); 50 trials 


\subsection{Effect of variation of tie-line power flow}

By increasing the power transfer limit between the three areas of the 10-unit system, the operating cost for the same load can be reduced as cheaper generators generate more and transfer the surplus power to the deficient area. Table 9 shows using DE that the operating cost can be reduced from $\$ 637.4111 / \mathrm{hr}$ to $\$ 630.9390 / \mathrm{hr}$ if the inter area tie line limit is increased uniformly from $100 \mathrm{MW}$ to $150 \mathrm{MW}$. The cost drops further to $\$ 623.6298$ if the limit is raised to $200 \mathrm{MW}$.

Table 9. Effect of variation of Tie line limits

\begin{tabular}{|l|l|l|l|}
\hline Tie line & $100(\mathrm{MW})$ & $150(\mathrm{MW})$ & $200(\mathrm{MW})$ \\
\hline P1(MW) & 215.9300 & 239.4103 & 218.2328 \\
\hline P2(MW) & 210.8343 & 221.2633 & 211.8571 \\
\hline P3(MW) & 484.3316 & 343.0598 & 280.7010 \\
\hline P4(MW) & 238.9041 & 246.2666 & 239.6262 \\
\hline P5(MW) & 249.1304 & 274.2847 & 278.4674 \\
\hline P6(MW) & 234.3569 & 238.8752 & 239.6262 \\
\hline P7(MW) & 260.3054 & 284.5275 & 288.5558 \\
\hline P8(MW) & 234.3569 & 238.8750 & 239.6262 \\
\hline P9(MW) & 325.3913 & 342.6461 & 428.4696 \\
\hline P10(MW) & 246.4592 & 270.7916 & 274.8378 \\
\hline T12(MW) & 100.000 & 150.0000 & 160.4671 \\
\hline T23(MW) & -100.000 & -150.000 & -239.116 \\
\hline T31 $(\mathrm{MW})$ & 31.2073 & 27.3127 & 28.8177 \\
\hline Cost $(\$ / \mathrm{h})$ & 637.4111 & 630.9390 & 623.6298 \\
\hline
\end{tabular}

Table 10. Comparison of Classic DE variants with PSO and PSO_TVAC (4-unit system;50 trials)

\begin{tabular}{|c|c|c|c|c|}
\hline Strategy & Minimum Cost & Me an Cost & Maximum Cost & S.D. \\
\hline $\mathrm{DE} /$ best $/ 1$ & 10609.1576 & 2032406.3572 & 40412074.3682 & 3068046 \\
\hline $\mathrm{DE} / \mathrm{r}$ and $/ 1$ & 10604.6740 & 10613.358 & 10907.3789 & 16.2773 \\
\hline $\mathrm{DE} / \mathrm{r}$ and to best $/ 1$ & 10604.6740 & 10604.6740 & 10604.6740 & $7.4942 \mathrm{e}-012$ \\
\hline $\mathrm{DE} /$ best $/ 2$ & 10604.6740 & 227535.3582 & 8811106.3587 & 412005 \\
\hline $\mathrm{DE} / \mathbf{r a n d} / 2$ & 10604.6740 & 10607.3482 & 10726.3591 & 4.7648 \\
\hline PSO & 10605.2022 & 10752.5428 & 10917.6879 & 133.5446 \\
\hline PSO-TVAC & 10604.6781 & 10717.5431 & 10864.3588 & 27.8354 \\
\hline
\end{tabular}

Table 11. Comparison of Classic DE variants with PSO and PSO_TVAC (10-unit system;50 trials)

\begin{tabular}{|c|r|r|r|r|}
\hline Strategy & Minimum Cost & Mean Cost & Maximum Cost & S.D. \\
\hline $\mathrm{DE} /$ best $/ \mathbf{1}$ & 638.9457 & 654.9837 & 677.6207 & $\mathbf{1 5 . 3 8 8 7}$ \\
\hline $\mathrm{DE} / \mathbf{r a n d} / \mathbf{1}$ & 638.5622 & 641.2084 & 645.2246 & $\mathbf{1 . 9 6 0 5}$ \\
\hline $\mathrm{DE} / \mathbf{r a n d}$ to best $/ \mathbf{1}$ & $\mathbf{6 3 7 . 4 1 1 1}$ & $\mathbf{6 3 7 . 4 1 1 1}$ & $\mathbf{6 3 7 . 4 1 1 1}$ & $\mathbf{3 . 9 5 6 3 e - 0 1 2}$ \\
\hline $\mathrm{DE} /$ best $/ \mathbf{2}$ & 677.6498 & $\mathbf{1 4 2 3 . 9 3 0 8}$ & 3475.0306 & 820.4701 \\
\hline $\mathrm{DE} / \mathbf{r a n d} / 2$ & 5814.0845 & 60390.84 & $\mathbf{1 2 6 5 1 0 . 5 0 8 7}$ & $\mathbf{4 1 9 3 9 . 0 4 5 4}$ \\
\hline PSO & 649.3495 & 706.5991 & 813.5806 & 34.6467 \\
\hline PSO-TVAC & 637.5915 & 647.4455 & 694.4076 & 22.2389 \\
\hline
\end{tabular}


Table 12. Time (cpu seconds) comparison of DE, PSO and PSO_TVAC

\begin{tabular}{|l|l|l|l|}
\hline & DE & PSO & PSO_TVAC \\
\hline 2 -are a 4-unit & 30.1875 & 9.3012 & 9.3594 \\
\hline 3 -are a, 10 unit & 90.5000 & 12.4176 & 13.1406 \\
\hline 2 area, 40 unit & 423.3434 & 123.4312 & 128.8332 \\
\hline
\end{tabular}

Table 13. Comparison of best results of evolutionary strategies for 4-unit system

\begin{tabular}{|l|l|l|l|l|l|l|l|l|}
\hline Strategy & $\mathrm{P} 1$ & $\mathrm{P} 2$ & $\mathrm{P} 3$ & $\mathrm{P} 4$ & $\mathrm{P} 12$ & $\mathrm{Cost}_{(\$ / \mathrm{H})}$ & $\mathrm{V}^{*}$ & $\mathrm{~V}^{*}$ \\
\hline $\begin{array}{l}\text { CMAES(Manoharan } \\
\text { et al.2009) }\end{array}$ & 560.9383 & 168.9300 & 99.9890 & 290.1427 & $\mathbf{- 1 9 4 . 3 9}$ & $\mathbf{1 0 5 7 4}$ & $\mathbf{1 4 0 . 0 0}$ & $-\mathbf{- 1 4 0 . 0 0}$ \\
\hline DE & $\mathbf{4 4 5 . 1 2 2 3}$ & 138.8777 & 212.0427 & 323.9573 & -200.0000 & 10604.6740 & 0.0000 & 0.0000 \\
\hline PSO-TVAC & 444.8047 & 139.1953 & 211.0609 & 324.9391 & -200.0000 & 10604.6781 & 0.0000 & 0.0000 \\
\hline PSO & 449.4771 & 134.5786 & 202.0271 & 333.9173 & -199.9443 & 10605.2022 & 0.0000 & 0.0000 \\
\hline
\end{tabular}

*V1 and V2 are area power balance violations for the two areas

Table 14. Comparison of best results of evolutionary strategies for 10-unit system with multiple fuel options

\begin{tabular}{|c|c|c|c|c|}
\hline Tie line & DE & PSO-TVAC & PSO & $\begin{array}{r}\text { CMAES (Manoharan } \\
\text { et al.2009) }\end{array}$ \\
\hline P1 (MW) & 215.9300 & 152.9295 & 121.9659 & 249.8233 \\
\hline $\mathrm{P} 2(\mathrm{MW})$ & 210.8343 & 272.8974 & 264.9114 & 229.8882 \\
\hline P3 (MW) & 484.3316 & 491.9497 & 500.0000 & 500.0000 \\
\hline P4(MW) & 238.9041 & 232.2235 & 265.0000 & 256.4765 \\
\hline P5 (MW) & 249.1304 & 245.5643 & 240.1560 & 227.5199 \\
\hline $\mathrm{P} 6(\mathrm{MW})$ & 234.3569 & 265.0000 & 196.1941 & 230.7744 \\
\hline P7(MW) & 260.3054 & 214.5668 & 236.7726 & 242.7438 \\
\hline P8(MW) & 234.3569 & 227.3739 & 234.9414 & 229.4518 \\
\hline P9(MW) & 325.3913 & 346.2924 & 440.0000 & 223.1725 \\
\hline P10(MW) & 246.4592 & 251.2024 & 200.0586 & 310.1497 \\
\hline T12(MW) & 100.000 & 100.0000 & 98.1227 & 96.5661 \\
\hline $\mathrm{T} 23(\mathrm{MW})$ & -100.000 & -100.0000 & -100.0000 & 25.7853 \\
\hline T31 (MW) & 31.2073 & 49.8688 & 100.0000 & 0.0419 \\
\hline $\operatorname{Cost}(\$ / h)$ & 637.4111 & 637.4989 & 649.3495 & 686.9850 \\
\hline Violation Area 1 & 0.0000 & 0.0000 & 0.0000 & -43.0312 \\
\hline Violation Area 2 & 0.0000 & 0.0000 & 0.0000 & -70.4861 \\
\hline Violation Area 3 & 0.0000 & 0.0000 & 0.0000 & 113.5174 \\
\hline
\end{tabular}

\subsection{Comparative analysis}

A detailed study of classic DE variants is carried out to judge their merit for the complex MAED problems. Table 10 and table 11 show the best results out of 50 trials for these strategies. Observing the minimum cost and standard deviation it can be concluded that out of the DE variants, the "DE/rand to best $/ 1$ " strategy performs the best for all the systems followed by $\mathrm{DE} / \mathrm{rand} / 1$ and $\mathrm{DE} / \mathrm{rand} / 2$ strategies. The $\mathrm{DE} /$ best $/ 1$ and $\mathrm{DE} /$ best $/ 2$ strategies do not converge in most trials. PSO_TVAC strategy gives better performance than the classical PSO and unlike DE convergence is achieved for all values of acceleration coefficients. 
Another significant difference is that DE requires less population but takes larger number of iterations to converge while PSO works with larger populations and lesser iterations as reported in Table 12. Table 13 and Table 14 give the comparison of reported results with already published results. The superiority of the reported results is evident from their ability to satisfy all constraints and produce feasible results. The solution reported in Manoharan et al. (2009) by the CMAES method satisfies the power balance constraint but the individual area balance constraints are violated.

\subsection{Performance on a large system}

The performance of DE and PSO strategies is also tested on a large system for ED with tie-line constraints and area power balance constraints. Fig. 7 shows the cost/MW of generators in the two areas. The overall cost will be heavily influenced by tieline limits, area loads and cost curves. The problem is complex as the unit valve point effects are also considered. Cost curves for some generators are plotted in Fig. 8 to show the effect of valve point loading effects. The DE and PSO_TVAC strategies could handle this complex problem effectively, with full constraint satisfaction, but the S.D. increases for both. The optimal generation schedules, the tie line power flow and operating cost for this system are tabulated in Table 15 for different loading conditions. Fig. 9 shows the best results of 50 different trials for DE, PSO and PSO_TVAC. The DE strategy is most consistent followed by PSO_TVAC.

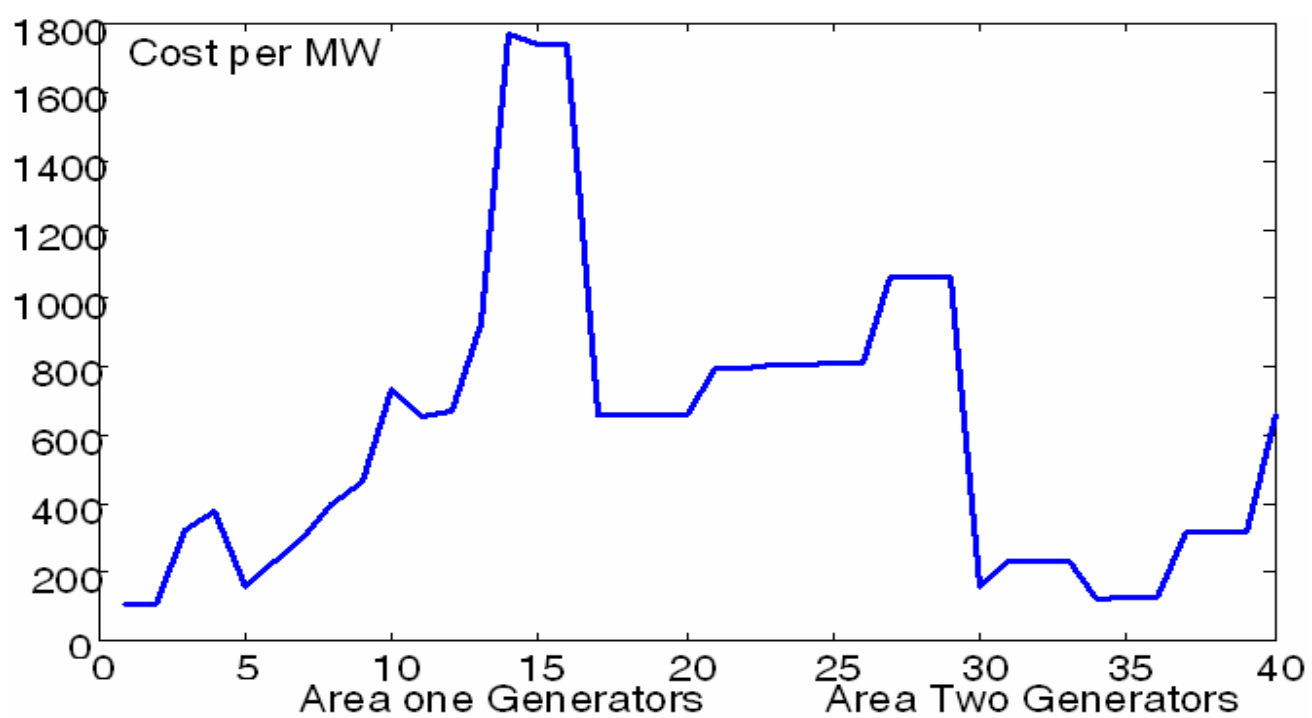

Figure 7. Per MW generation cost of 2-area, 40 unit system

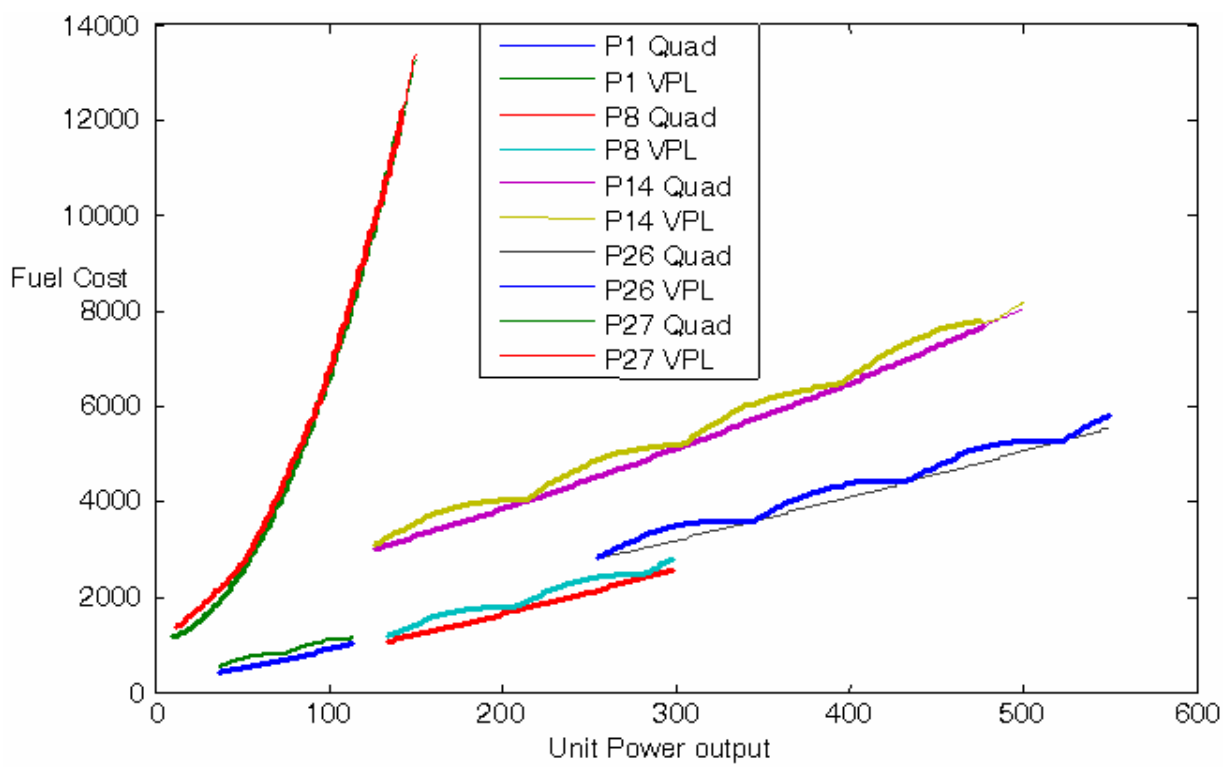

Figure 8. Cost characteristics of some generators of the 2-area 40-unit system with valve point loading 


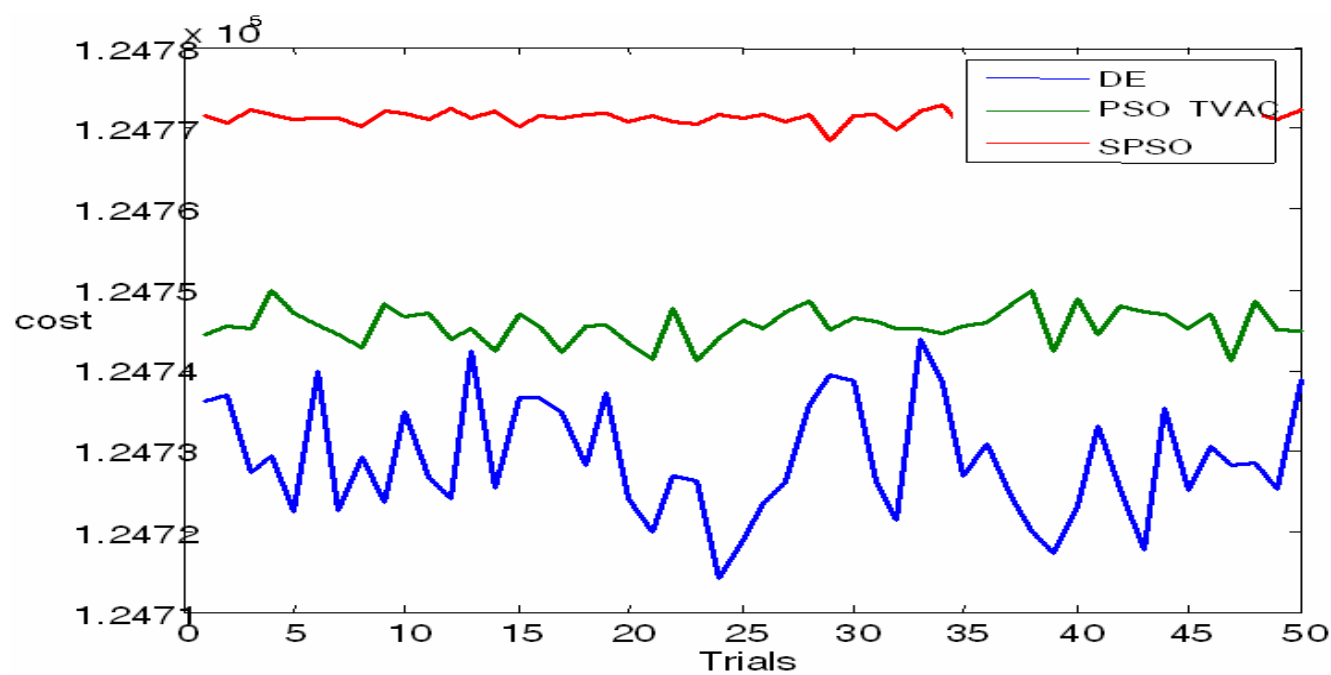

Figure 9. Best results of DE, PSO and PSO_TVAC variants (40-unit system); 50 trials

Table 15. DE Results for 2-area, 40-unit system with valve point loading effects

\begin{tabular}{|c|c|c|c|c|c|c|c|}
\hline \multicolumn{4}{|c|}{$\mathrm{PD} 1=6000, \mathrm{PD} 2=4500$} & \multicolumn{4}{|c|}{$\mathrm{PD} 1=6500, \mathrm{PD} 2=4000$} \\
\hline P1 & 72.6735 & P22 & 512.3591 & P1 & 110.6035 & P22 & 343.6729 \\
\hline P2 & 110.7950 & P23 & 522.9567 & P2 & 110.8448 & P23 & 343.6756 \\
\hline P3 & 97.4138 & P24 & 523.1559 & P3 & 119.0457 & P24 & 523.2895 \\
\hline P4 & 179.5084 & P25 & 522.1513 & P4 & 129.5861 & P25 & 523.2779 \\
\hline P5 & 87.7555 & P26 & 523.1610 & P5 & 96.7378 & P26 & 433.5002 \\
\hline P6 & 105.1929 & P27 & 10.0757 & P6 & 139.9824 & P27 & 10.0649 \\
\hline P7 & 260.3616 & P28 & 10.1302 & P7 & 259.6255 & P28 & 10.0002 \\
\hline P8 & 285.6335 & P29 & 10.0152 & P8 & 284.6046 & P29 & 10.0179 \\
\hline P9 & 209.7219 & P30 & 47.0502 & P9 & 284.5867 & P30 & 87.9075 \\
\hline P10 & 279.6238 & P31 & 158.5759 & P10 & 279.6250 & P31 & 159.7272 \\
\hline P11 & 243.5351 & P32 & 159.5359 & P11 & 318.3928 & P32 & 159.6096 \\
\hline P12 & 168.7127 & P33 & 159.6218 & P12 & 318.3144 & P33 & 109.8664 \\
\hline P13 & 484.1367 & P34 & 189.2346 & P13 & 483.4463 & P34 & 114.8240 \\
\hline P14 & 393.9142 & P35 & 164.9628 & P14 & 483.5403 & P35 & 164.7162 \\
\hline P15 & 394.1924 & P36 & 164.3703 & P15 & 484.0276 & P36 & 90.0228 \\
\hline P16 & 393.9511 & P37 & 57.0693 & P16 & 483.2328 & P37 & 25.0026 \\
\hline P17 & 489.2049 & P38 & 87.4335 & P17 & 489.2594 & P38 & 57.0734 \\
\hline P18 & 489.2597 & P39 & 48.9374 & P18 & 489.2182 & P39 & 57.0582 \\
\hline P19 & 511.3221 & P40 & 421.0089 & P19 & 545.6891 & P40 & 421.5172 \\
\hline P20 & 518.1037 & T12(Tieline) & 0.0124 & P20 & 511.2953 & T12 (Tieline) & -78.3417 \\
\hline P21 & 433.1825 & - & - & P21 & 433.5177 & - & - \\
\hline S.D. & & 1.7012 & & S.D. & & 1.7634 & \\
\hline Cost $\$ / \mathrm{H}$ & & 124714.2876 & & Cost $\$ / H$ & & 128138.0739 & \\
\hline $\mathrm{V} 1^{*}$ & & 0.0000 & & $\mathrm{~V} 1{ }^{*}$ & & 0.0000 & \\
\hline $\mathrm{V} 2^{* *}$ & & 0.0000 & & $\mathrm{~V} 2^{* *}$ & & 0.0000 & \\
\hline
\end{tabular}




\section{Conclusions}

Evolutionary strategies are increasingly being proposed for solving non-convex, discontinuous, multi-modal ED problems with complex constraints. In multi-area ED problem additional tie-line and area balance constraints are introduced which present difficulty in obtaining feasible solutions. The paper explores the ability of DE and PSO strategies to produce global best solutions for the complex MAED problems. A comparative study of classic DE variants with PSO and its variants is made to find their abilities and limitations. Simulations on three systems of different sizes and areas, having different complexity levels clearly reveal that

- The DE/rand to best/1 strategy performs best for all tested systems closely followed by DE/rand/1 and DE/rand/2 strategies. The other DE variants do not converge for MAED problems.

- PSO_TVAC and classic PSO converge to near global solutions in all trial runs, for all tested values of tuning parameters though global best performance is not guaranteed; but the S.D. is higher than DE.

- DE converges to the global best solution with zero S.D. in a very narrow range of tuning parameters. For other combinations it either diverges or produces low quality solutions; hence very little parameter tuning is required in DE as compared to PSO and its variants which work for a very broad range of acceleration coefficients.

- DE works with lesser population size but require more number of iterations to converge while the PSO and PSO_TVAC require larger populations but converge earlier.

- Due to their speed and efficiency, the evolutionary optimization algorithms prove to be very effective in analyzing the effect of tie-line power limits on the cost of operation.

It is shown through different trials that the DE outperforms other methods, particularly for MAED problems, in terms of solution quality, computational efficiency, dynamic convergence, robustness and stability.

\section{Acknowledgement}

The authors sincerely acknowledge the financial support provided by University Grants Commission (UGC), New Delhi, India under major research project entitled Power System Optimization and Security Assessment Using Soft Computing Techniques, vide F No.34-399/2008 (SR) dated, 24th December 2008 and AICTE New Delhi, India for financial assistance under RPS project F No 8023/RID/BOR/RPS-45/2005-06 dated 10/03/2006. The authors also thank the Director, M.I.T.S. Gwalior for providing facilities for carrying out this work.

\section{References}

Alrashidi M.R. and El-Hawary M.E.2007. Hybrid particle swarm optimization approach for solving the discrete OPF problem considering the valve loading effects, IEEE Trans. on Power Systems, Vol. 22, No. 4, pp. 2030-2038.

Chaturvedi Krishna Teerth, Pandit Manjaree and Srivastava Laxmi. 2009. Particle swarm optimization with time varying acceleration coefficients for nonconvex economic power dispatch, Electrical Power and Energy Systems, Vol. 31, No.6, pp. 249-257.

Chaturvedi Krishna Teerth, Pandit Manjaree and Srivastava Laxmi 2008. Self-organizing hierarchical particle swarm optimization for nonconvex economic dispatch, IEEE Transactions on Power System, Vol. 23, No. 3, pp. 1079-1087.

Chen C.L. and Chen N. 2001.Direct search method for solving economic dispatch problem considering transmission capacity constraints, IEEE Transactions on Power System, Vol. 16, No. 4, pp. 764-769.

Cheng S.-L. and Hwang C.2001. Optimal approximation of linear systems by a differential evolution algorithm, IEEE Trans. Syst., Man, Cybern.A, Syst., Humans, Vol. 31, No. 6, pp. 698-707.

Coelho Leandro dos Santos and Mariani Viviana Cocco 2006. Combining of chaotic differential evolution and quadratic programming for economic dispatch optimization with valve-point effect, IEEE Trans. Power System, Vol. 21, No. 2, pp. 989996.

Desell A.L., Tammar K., McClelland E.C. and Van Home P.R. Transmission constrained production cost analysis in power system planning, 1984. IEEE Trans. on Power Apparatus and Systems, Vol. PAS-103, No. 8, pp. 2192-2198.

Doty K.W. and McEntire P.L. 1982 .An analysis of electrical power brokerage systems, IEEE Trans Power Apparatus System, Vol. 101, No.2, pp. 389-396.

Farmer E.D., Grubb M.J. and Vlahos K. 1990. Probabilistic production costing of transmission-constrained power systems, 10th PSCC Power System Computation Conference, pp. 663-669.

Hemick SD,Shoults RR. 1985. A practical approach to an interim multi-area economic dispatch using limited computer resources. IEEE Trans Power Apparatus System, Vol. 104, No. 6, pp. 1400-1404

Jayabarathi T., Sadasivam G. and Ramachandran V. 2000. Evolutionary programming based multi-area economic dispatch with tie-line constraints, Electrical Machines and Power Systems, Vol. 28, pp.1165-1176.

Kennedy J and Eberhart R.1995. Particle swarm optimization. Proc. IEEE Conf. on Neural Networks (ICNN’95), Vol. IV, Perth, Australia, pp. 1942-48. 
Lin C.E.and Viviani G.L.1984. Hierarchical economic load dispatch for piecewise quadratic cost functions, IEEE Transactions Power Apparatus and systems, Vol. PAS-103, pp.1170-1175.

Manoharan P.S., Kannan P.S., Baskar S., Iruthayarajan M. Willjuice. 2009. Evolutionary algorithm solution and KKT based optimality verification to multi-area economic dispatch, Electrical Power and Energy Systems, Vol. 31, pp. 365-373.

Noman Nasimul and Iba Hitoshi.2008. Differential evolution for economic load dispatch problems, Electric Power Systems Research, Vol. 78, pp. 1322-1331.

Orero SO and Irving MR. 1996. Economic dispatch of generators with prohibited operating zones: a genetic algorithm approach. IEE proceedings Generation, Transmission and Distribution, Vol. 143, No.6, pp. 529-33.

Panigrahi B.K. and Pandi V. Ravikumar 2009. Bacterial foraging optimisation: Nelder-Mead hybrid algorithm for economic load dispatch, IET Generation, Transmission and Distribution, Vol. 2, No. 4, pp. 556-565.

Park J.H., Kim Y.S., Eom I.K., Lee K.Y. 1993.Economic load dispatch for piecewise quadratic cost function using Hopfield neural network, IEEE Transactions on Power Systems, Vol. 8, pp. 1030-1038.

Ratnaweera A., Halgamuge S.K. and Watson H.C.2004.Self-organizing hierarchical Particle swarm optimizer with time varying acceleration coefficients, IEEE Trans Evol Computation, Vol. 8, No. 3, pp. 240-255.

Shoults R.R., Venkatesh S.V., Helmick S.D., Ward G.L., Lollar M.J. 1986. A dynamic programming based method for developing dispatch curves when incremental heat rate curves are non-monotonically increasing. IEEE Trans Power Syst., Vol. 1, No. 1, pp. 10-16.

Shoults R.R., Chang S.K., helmick S. and Grady W.M. 1980.A practical approach to unit commitment, economic dispatch and savings allocation for multiple area pool operation with import/export constraint, IEEE Transactions on Power Apparatus and Systems, Vol. 99, No.2, pp. 625-35.

Sinha N., Chakraborty R. and Chattopadhyay P.K.2003.Evolutionary programming techniques for economic load dispatch", IEEE Transactions on. Evolutionary Computation, Vol. 7, No.1, pp. 83-93.

Song YS, Chou CS and Stoham TJ. 1999.Combined heat and power economic dispatch by improved ant colony search algorithm. Electric Power Systems Research, Vol. 52, No.2, pp. 115-121

Storn R. and Price K.1995.Differential evolution, A simple and efficient adaptive scheme for global optimization over continuous spaces, International Computer Science Institute, Berkeley, CA, Tech. Rep. TR-95-012.

Storn R.1997.Differential evolution — a simple and efficient heuristic for global optimization over continuous spaces, J. Global Optimization., Vol. 11, No. 4, pp. 341-359.

Streifferet Dan. 1995. Multi-Area economic dispatch with tie-line constraints. IEEE Transactions on Power Systems, Vol. 10, No. 4, pp. 1946-1951.

Vanaja B., Hemamalini S. and Simon S.P. 2008. Artificial immune based economic load dispatch with valve-point effect, IEEE Region 10 Conference, TENCON 2008, pp. 1-5.

Vasebi A., Fesanghary M., Bathaee S.M.T. 2007.Combined heat and power economic dispatch by harmony search algorithm, Electrical Power and Energy systems, Vol. 29, pp. 713-719.

Walter D.C. and Sheble G.B.1993 Genetic algorithm solution of economic load dispatch with valve point loading, IEEE Transactions on Power Systems, Vol. 8, No. 3, pp. 1325-1332.

Wang C, Shahidehpour SM. 1992. A decomposition approach to non -linear multi-area generation scheduling with tie-line constraints using expert system. IEEE Trans Power Apparatus System, Vol. 7, No. 4, pp. 1409-1418

Wernerus J. and Soder L. 1995.Area price based multi-area economic dispatch with tie-line losses and constraints, IEEE/KTH Stockholm Power Tech Conference. Sweden, pp.710-15.

Wood A. J. and Wollenberg B.F. 1984. Power generation, operation and control, John Wiley \& Sons.

Yalcinoz T. and Short M. J. 1998. Neural networks approach for solving economic dispatch problem with transmission capacity constraints, IEEE Transactions on Power Systems, Vol. 13, No. 2, pp. 307-313.

Biographical notes:

Manisha Sharma obtained her M.E. degree in Electrical Engineering from Madhav Institute of Technology \& Science Gwalior (India) in 2007. She is currently working as Project Fellow in the Department of Electrical Engineering, M.I.T.S., Gwalior (India) in the area of Evolutionary Computation applications.

M. Pandit obtained her M.Tech degree in Electrical Engineering from Maulana Azad College of Technology, Bhopal, (India) in 1989 and Ph.D. degree from Jiwaji University Gwalior (India) in 2001. She is currently working as Professor in Department of Electrical Engineering, M.I.T.S., Gwalior, (India). Her areas of interest are Power System Security Analysis, Optimization and soft computing/ evolutionary methods, ANN and Fuzzy neural applications to Power System.

L. Srivastava obtained her M. Tech. degree in Electrical Engineering from the Indian Institute of Technology, Kanpur, India in 1990 and her Ph.D. degree from University of Roorkee (Presently IIT Roorkee), Roorkee, India in 1998. She is working as a professor in the Department of Electrical Engineering, M.I.T.S. Gwalior, India. She is currently involved in research in power system optimization and control, security analysis, operation and control of deregulated power systems, and ANN and fuzzy logic applications to power system.

Received December 2009

Accepted March 2010

Final acceptance in revised form March 2010 